\title{
Organizational Citizenship Behaviour and Employees' Performance Assessment: The Case of Dire Dawa University
}

\author{
Desta Dirbeba Dinka \\ Chemistry Department, Dire Dawa University, Dire Dawa, Ethiopia \\ Email address: \\ destad24@gmail.com \\ To cite this article: \\ Desta Dirbeba Dinka. Organizational Citizenship Behaviour and Employees' Performance Assessment: The Case of Dire Dawa University. \\ American Journal of Theoretical and Applied Business. Vol. 4, No. 1, 2018, pp. 15-26. doi: 10.11648/j.ajtab.20180401.13
}

Received: November 19, 2017; Accepted: November 30, 2017; Published: March 8, 2018

\begin{abstract}
Although a vast amount of researches have been done on the relations of Organizational Citizenship Behavior (OCB) and employees' performance in western or foreign context, there is a little or no empirical evidence in domestic context. However, scholars argue that geographical and cultural differences can bring about differences in OCB. Thus, this empirical study was conducted to find out the relationship between employees' performance and OCB in Ethiopian context, particularly in Dire Dawa. The study was also aimed at investigating the underlying reasons for imperceptibility of OCB in Dire Dawa University. A stratified random sampling technique was used to select 114 employees as the representative sample of the study. The standardized measurement scales were adapted for Liker scale questions and distributed to the employees. Spearman correlation was used to test the co-relational hypotheses while percentage and graphs were employed for the purpose of descriptive analysis. The findings showed that employee's performance is correlated positively and significantly to the OCB dimensions. Furthermore, organizational justice problems and employee's intention to the leave the institution were found to be the major underlying reasons for imperceptibility of OCB among the employees under the study while fairness perception, individual disposition and proper leadership styles, on the other hand, were shown to be the major enabling factors for OCB among employees in the institution's context.
\end{abstract}

Keywords: Organizational Citizenship Behavior, Employees Performance, Organizational Justice, Employees Intentions

\section{Introduction}

As it is known, universities are producing educated manpower, not commodities. Individuals who work in different sectors in a country are the fruit of universities and colleges. The qualities of services rendered by public universities are highly influenced by their employees' commitment and sense of ownership. Individuals who take initiation to go beyond their normal roles and job description (OCB) are critically important in higher institutions for quality output and effectiveness of universities [1].

Alkahtani [2] clearly pointed out that a single major reason why Organizational Citizenship Behavior (OCB) has attracted the attention of many academicians and practitioners is due to its proven significance towards organizational effectiveness [2]. Podsakoff [3] and his coworkers summarized that organizational citizenship behavior affects organizational performance by improving the efficiency of colleagues and managers; enhancing effective utilization of resources for more productive activities and objectives; assisting team coordination for productive work; making organizations more responsive to change in the environment; strengthening the ability in attracting and retaining talented employees and enhancing the stability of the organization [3]. Consequently, the effect of OCB dimensions on employee's performance or relationship between OCB dimensions and employee's performance has been extensively studied. However, most of such empirical studies are correlational analyses with few emphases on what could be the underlying reasons in case OCB is imperceptible (seldom observable) in a given organization within a given geographical area. Another important aspect which has not got much attention is that OCB enacted differently in different cultures [4]. The implication is that an OCB- 
encouraging factor in a given culture may not necessarily be an encouraging factor in another culture. Furthermore, Bukhari et al. [5] argues that different geographical contexts have different culture, values, norms and environment which necessitate a separate study for better understanding of OCB [5]. As a result, this research work was targeted at investigating reasons for imperceptibility of OCB in Ethiopian context, particularly in Dire Dawa University, and contributing factors to foster $\mathrm{OCB}$ in the university. Furthermore, the assessment of the relationship between employees' performance and the three dimensions of OCB (altruism, conscientious and civic virtue) was addressed.

\section{Literature Framework and Hypotheses}

\subsection{Employee Performance}

Employee performance or job performance is aggregated value to an organization of the set of behaviors that an employee contributes both directly and indirectly to organization goals [6]. Performance refers to the degree of success in implementing the tasks and the ability to achieve the intended purpose [7]. As explained in study of Nyarieko [8] employees' performance is basically the results gained and completion by employees at workplace that keeps up organizational plans though aiming for the expected outcomes [8]. In broad sense, performance is viewed as valued outputs of a production system in the form of goods or services. In today's business environment, organizations continuously compete for achieving excellence by enhancing their employee's performance. Organizations can get this with the extreme support of their employees [9]. It is explained in terms of the following measures: productivity, efficiency, effectiveness, and quality and profitability measures [10]. Employee performance is the important factor and the building block which increases the performance of overall organization [11].

\subsection{Organizational Citizenship Behavior (OCB)}

Organ [12] defines OCB as voluntary behavior, choice and individual initiatives that are not directly related to the formal reward system of the organization, but as a whole can improve the organizational effectiveness. According to Jahangir, OCB is set of discretionary workplace behaviors that exceed one's basic job requirements; they are behaviors that go beyond the call of duty [13]. Bolino et al. [14] defines OCB as employee behavior that the influence of interpersonal trust and facilitates organizational operation by going beyond official requirements which are not directly recognized by the formal reward system without expecting any rewards and appreciation. OCB involves some elements of behavior such as helping others, volunteering for extra duties, and adhere to the rules and procedures in the workplace. These behaviors are constructive, meaningful and positive social behaviors [15].

The belief among theorists is that as more employees engage in $\mathrm{OCB}$, the organization becomes more successful.
OCB is positively related to individual, group and organizational performances [16].

Therefore, OCB plays an essential role for the success of an organization. OCB can influence organizational performance, improves group performance because it helps people to work together. Employees who help each other do not have to ask the boss for help which allows the tops are free of duties more important [2, 3]. In today's highly competitive environment, organizations are accentuating on areas that can help them achieving competitive edge and OCB is one of such areas [9].

\subsection{Dimensions of Organizational Citizenship Behavior}

Since its inception in 1983, OCB has been classified into different dimensions. OCB was originally organized into two dimensions: altruism and compliance [17]. Compliance was later renamed conscientiousness. In 1988, Organ added sportsmanship, courtesy, and civic virtue. In 1994, Dyne and his co-workers classified the construct into three dimensions: obedience, loyalty and participation [18]. More recently, it was classified into seven dimensions by Podsakoff and his co-authors [3]. However, the Organ (1988)'s classification is most frequently cited in literatures and as a result that classification was made use of in this particular research. According to Bukhari et al [5] altruism, conscientious and civic virtue are the three dimensions which have a significant relationship with OCB. Borman et al. [6] also stated that altruism and conscientiousness are the two overarching dimensions of OCB. It is this basis the researcher interested only in altruism, conscientiousness and civic virtue dimensions.

\subsubsection{Altruism}

It is helping behavior that includes all types of voluntary actions of workmen displayed to help the fellow workmen in performing their work and overcoming problems within the organization [19]. Examples of this attitude include helping beginners in getting used to work, sharing the work burden of fellow workmen, helping others in solving problems, training fellow workmen on utilization of new equipment and helping fellow workmen to works for required deadlines [3]. The helping behavior is not confined only to fellow workmen; it can also be shown toward customers and vendors [19;3]. As stated by Koster [20], altruism reduces monitoring costs and enhances cooperation. As a result, organizations benefit from employees' altruistic behavior [20]. Generally, employees with greater altruistic behaviors will make more efforts in job performance and show a better job performance [21]. Chelagat et al. [22] studied the effect of organizational citizenship behavior on employee performance in banking sector in Nairobi and they identified that altruism is positively and significantly correlated with employee performance. Previous studies of Hsiung [21]; Barrick et al. [23] and Bukhari et al. [5] are empirically in agreement with that of Chelagat et al. (2015) both in direction and strength. However, the findings of Baghkhasti and Enayati [11] are in sharp contrast to the above findings with respect to the 
relationship between employee performance and altruism as they showed that there is no significant correlation between the two variables [11]. The first hypothesis was stated follows taking into account the above discussion.

Hypothesis 1: There is a significant and strong relationship between altruism and employee's performance.

\subsubsection{Conscientiousness}

Organ [19] defined it as dedication to the job which exceed formal requirements such as working long hours, and volunteer to perform jobs besides duties. In other words, conscientiousness means the thorough adherence to organizational rules and procedures, even when no one is watching [5]. Conscientiousness can be expressed in the form of certain role behaviors, e.g. displaying certain behavior above what is expected, devotion to work and organization, low absenteeism levels, being careful deadlines, respecting and obeying procedures, rules, regulations even when there is no check and balance and a lot more $[4 ; 19)$.

Alsuwailem and Elnag [24] in their study of relationship between personality and job performance, they indicated that conscientiousness and employee performance have positive correlation. The work of Baghkhasti and Enayati [11] also is consistent with those of Alsuwailem and Elnag [24] as it showed significant relationship between employee performance and conscientiousness. Although there are very rare empirical findings that showed the no relationship or negative relationship between these two variables, the strength of the correlation almost always weak to moderate. The second hypothesis was set forth on the ground the above results.

Hypothesis 2: There is a significant and strong relationship between conscientiousness and employee's performance.

\subsubsection{Civic Virtue}

Civic Virtue' refers to behaviors that demonstrate a responsible concern for the image and well being of the organization [25]. Borman et al. [26] defines it as responsibly involving oneself in and being concerned about the life of the company. As explained in the work of Nyarieko et al. [8], employees exhibiting civic virtue behaviors are responsible members of the organization who actively engage in constructive involvement in the policies and governance of the organization. Civic virtue represents an employees' feeling of being part of the organizational whole in the same way a citizen feels a part of his or her country. An employee displaying civic virtue behaviors embraces the responsibilities of being a 'citizen' of the organization [3]. It is the behavior exposed by taking part in the meetings, showing interest in policies of the organization, making contributions and deliver opinions for the strategies of the organization, coping with the changes in organizational framework, observing environment for avoiding any hazard to the organization, reporting any unusual incidence in the workplace and being ready against any risk [4, 19].

Nyarieko et al. [8] studied the impact of OCB on casual employees' performance and their findings showed the employees' performance is positively and significantly correlated with civic virtue.

Like many other studies, the work of Nyarieko and his coworkers revealed a medium positive correlation between the two variables. Baghkhasti and Enayati [11] also obtained similar results with the aforementioned study both in direction and strength. However, Hazratian et al. [1] in their study of association between organizational citizenship behavior and educational performance of faculty members in Tabriz University of medical sciences in Iran, they showed that there is no significant relationship between civic virtue and educational performance.

Hypothesis 3: There is a significant and strong relationship between civic virtue and employee's performance.

\section{Research Methodology}

\subsection{Data Sources}

Primary data were collected from the target population, employees of Dire Dawa University, using questionnaire. To get the required information, researcher designed and distributed a set of questionnaire that represents the predictor variables and dependent variables which were extracted from established questionnaire. The questionnaires were distributed to sampling amount of academic staff and administrative employees.

\subsection{Research Design}

Research approach can be regarded as a blue print; a master plan that specifies the methods. Thus, every research requires a research design that is carefully tailored to the exact needs of the problem under investigation [27]. The research design for this study was the cross-sectional study as the data were collected at one time. Furthermore, the study was co-relational in design because there was an intention to establish the relationship between dependent and predictor variables of the study. The co-relational research aims to ascertain if there is a significant association between two variables.

\subsection{Sampling Technique and Sample Size}

In this research, probability sampling techniques was used. From probability sampling technique, stratified sampling was made use of to stratify the total population of 1761 into three strata as academic staff (417), administrative employees (1244), and management staff (100). Then, simple random sampling technique was be used to select the representative sample from each stratum.

As stated by Kothari [28], there are two alternative approaches for determining the size of the sample. The first approach is to specify the precision of estimation desired and then to determine the sample size necessary to insure it and the second approach uses Bayesian statistics to weigh the cost of additional information against the expected value of the additional information. The first approach is capable of giving a mathematical solution, and as such is a frequently 
used technique of determining the sample size. Hence, the first approach was used in this paper. In line with this, for determination of the sample size, the formula for calculating a sample for proportion was used as shown below.

$$
S S=\frac{Z^{2} x(p) x(1-p)}{e^{2}}
$$

SS stands for sample size, $\mathrm{p}$ stands for sample proportion and e stands level of precision required. Supposing the difference between the population $(\mu)$ and sample mean $(\bar{x})$ to be within +0.04 with $95 \%$ confidence level $(Z=1.96)$.

$$
\begin{aligned}
& \text { This gives us } \\
& S S=\frac{(1.96)^{2} \times(0.05) \times(1-0.05)}{0.04^{2}}=\frac{\left(1.96^{2}\right) \times(0.05) \times(1-0.05)}{0.04^{2}}=114
\end{aligned}
$$

Table 1. Sample size determination using proportionate stratified sampling.

\begin{tabular}{llll}
\hline Sample stratum & Population in the stratum & proportion & Sample from each stratum (Respective Proportion *114) \\
\hline Academic staff & 417 & $\frac{417}{1761}$ & 27 \\
Admin. employees & 1244 & $\frac{1244}{1761}$ & 80 \\
Management staff & 100 & $\frac{100}{1761}$ & 7 \\
Total & & & 114 \\
\hline
\end{tabular}

\subsection{Research Instruments}

This research study used primary data as the principal source of information in which individual employees of the University were considered as the unit of analysis. The study employed questionnaire as a method of data collection which consisted of 24 Likert scale questions and 3 additional questions which are not Likert scale. The 24 Likert scale questions were divided into six sections. Accordingly, the $1^{\text {st }}$, the $2^{\text {nd }}$, the $3^{\text {rd }}$, the $4^{\text {th }}$ and the $5^{\text {th }}$ sections represent organizational performance, altruism, civic virtue and conscientious, respectively. The questions were formed in a five point Likert scale such as $1=$ Strongly Disagree, 2= Disagree, 3 =Neutral, 4 =Agree, $5=$ Strongly Agree which allows respondents to indicate level of agreement with the statement provided. The 24 Likert scale questions are standard questions which were adapted from Chelagat et al. [22] and Sharma and Jain [29].

\subsection{Method of Data Analysis}

The collected data through questionnaire were analyzed using statistical techniques. The collected data were analyzed using SPSS 20 software version for both descriptive and for an inferential analysis. Test of normality were performed to determine the internal consistency of the instruments while Spearman correlation was employed for the purpose of testing the hypothesis. Percentages and bar graphs were also used to represent and interpret information obtained from respondents for questions other than Likert scale.

\section{Results}

In this chapter, the data which were collected from respondents through questionnaires were analyzed and discussed.

\subsection{Reliability Test Result}

The Cronbach's alpha coefficient is a statistical tool that evaluates the confidentiality through the inner consistency of a questionnaire. It is commonly used as a measure of the internal consistency or reliability of a psychometric test score for a sample of examinees. According to Tavakoland Dennick [30], the acceptable values of alpha range from 0.70 to 0.95 . The Cronbach's alpha values shown in table below were found to be above the lower limit. Thus, the reliability of each item is in the acceptable range.

Table 2. Cronbach's alpha coefficients for each item.

\begin{tabular}{lll}
\hline The study Variables & No of items & Cronbach's alpha \\
\hline Organizational performance & 6 & 0.83 \\
Altruism & 6 & 0.76 \\
Civic virtue & 6 & 0.75 \\
Conscientious & 6 & 0.79 \\
\hline
\end{tabular}

Source: Researcher's primary data.

\subsection{Descriptive Analysis}

In this section, responses to questionnaires other than Likert scale questionnaires which were prepared to address the research questions concerned with the reasons for imperceptibility of OCB, the enabling factors of OCB were analyzed using percentages and bar graphs.

\subsubsection{Reasons for Imperceptibility of $O C B$ in the Institution}

To assess whether OCB is obviously observable or imperceptible among the employees of the institution, the respondents were first asked a yes/no question. More than $90 \%$ of respondents responded that OCB is imperceptible in 
the institution. Those respondents who responded that OCB is imperceptible were further asked to suggest reasons for such imperceptibility. The reasons they enumerated were summarized in form of graph as shown below.

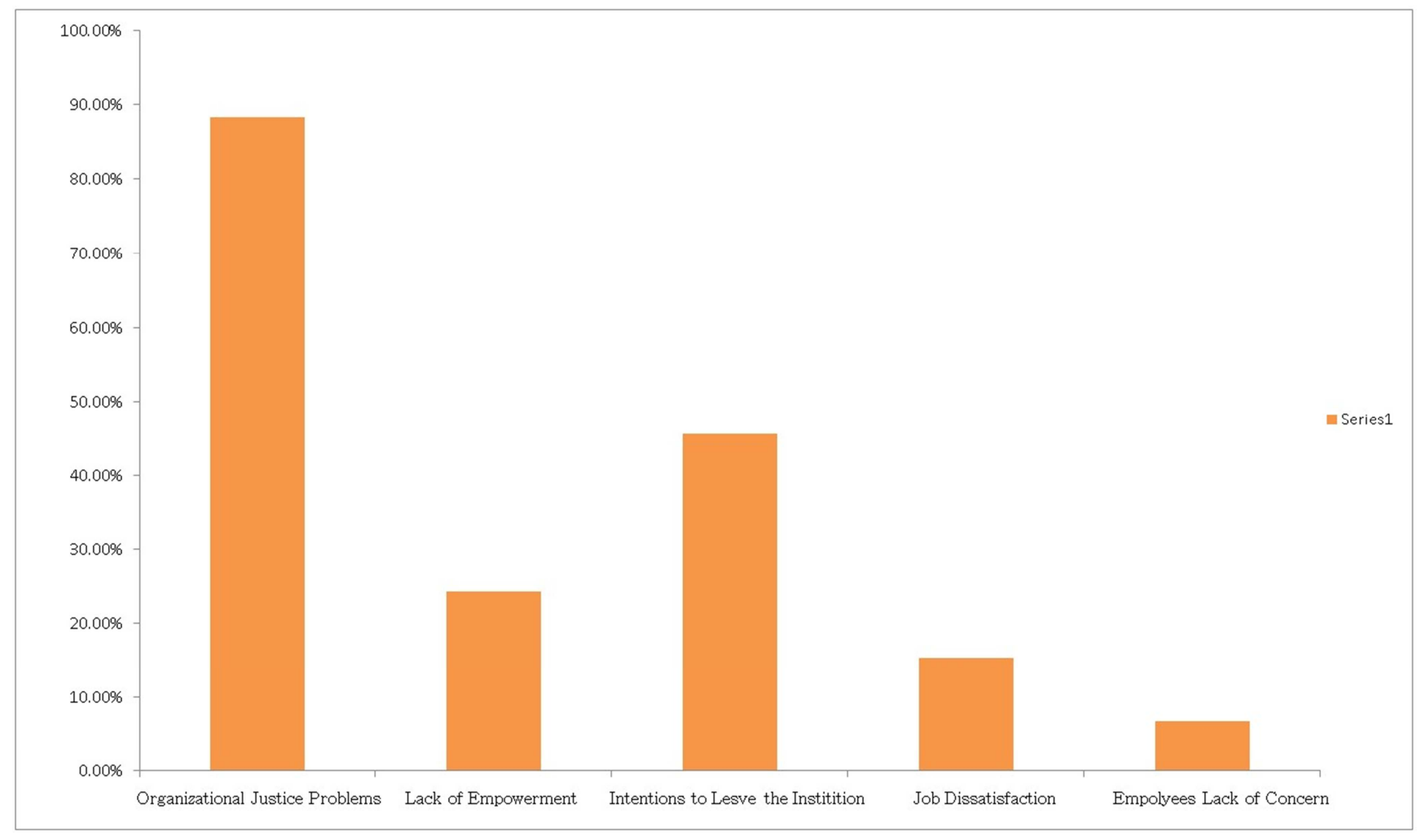

Figure 1. Reasons for Imperceptibility of $O C B$ in the Institution (Source: researcher's primary data).

As is it evident from the graph, the majority of the respondents $(88.35 \%)$ responded that the reason for the imperceptibility of OCB in the institution is organizational justice problems. Problems mentioned as organizational justice problems while question was being asked are lack of fair decisions by top level management, lack of fair payment for fair performance and lack fair treatment by top level manager. These three problems were included in the question so as to address whether there are problems in procedural, distributive and interaction justices. The next predictor variable with larger percentage (45.63) is employees' intention to leave the institution followed by lack of empowerment of the employees $(24.27 \%)$.

As result, it seems reasobale to futher consider these factors mainly affecting OCB in the institution to see whether there are theoretical concepts and empirical fndingsthat support this current results.

The primary condition for OCB is the perceptions of workers about the decision and practices in the organization they work. These perceptions set the trust of the workers into motion and then stiffen their citizenship behaviors.

The more justice perception means the more positive state of mind [31, 32, 33]. Williams et al. [34] asserts that the positive state of the mind increases the possibility of performing certain organizational citizenship behaviors. According to Moorman [35] organizational justice is about the organizational behaviors. The evaluation of the employees by their chiefs and their perceptions toward its fairness determine their organizational behaviors. He showed that the workers those perceive fair practices of managers provide more organizational citizenship behaviors. The consciousness of organizational citizenship behavior depends primarily on the organizational justice perception. According to Organ [32], by the help of distributive and procedural justice, it is easy to improve the organizational citizenship behavior among the employees. Employees tend to show less desire for organizational behaviors in case of unfair practices [31]. Alotaibi [31] conducted a study about the antecedents of OCB and he found that procedural justice and distributive justice has positive effect on Organizational Citizenship Behavior. Ince and Gul [33] conducted similar research and came out with similar finding that shows the organizational justice has positive correlation with OCB.

These all more likely suggest that the lack of organization justice in an organization may lead to the reverse scenario. Thus, there are a theoretical grounds and empirical findings that support the researcher to conclude that reason why OCB is imperceptible among the institutions' employees is most probably due to lack of organizational justice in the institution.

The second major predictor why OCB is seldom perceptible amongthe institution's employees is the employees' intention to leave the institution. Coyne and Ong [36] asserts that when employees experience lasting dissatisfaction with their organizations or jobs, but cannot leave due to lack of external professional opportunities; it is less risky for them to reduce OCBs than to express this 
discontent through diminishing efforts at work. Indeed, an employee who decreases efforts at work may face sanctions from a supervisor whereas employees who diminish their OCBs will not face sanctions, since OCBs are discretionary behaviors which are not formally required [37]. Previous research studies like that of Coyne and Ong [36]; Iftikhar et al. [37]; Chen et al. [38]) and many others showed employees' intentions to leave and OCB are negatively correlated. That means the more the intentions of the employees to leave their current organizations, the less OCB they provide.

This implies us that the second most probable to the imperceptibility of OCB among the employees in the institution is that employees have strong intention to leave which has led to the dwindling of sense of OCB.

The $3^{\text {rd }}$ predictor for the imperceptibility of OCB in the current study area is job dissatisfaction. The relationship between job satisfaction and OCB is exhaustively done and overanalyzed. There are two conceptual bases for thinking that job satisfaction affects OCB. The first one suggests that the satisfied individuals tend to experience positive mood states more frequently and thus they have a greater propensity to engage in extra-role behavior. The second conceptual base, which is the dominant explanation, depends on social exchange theory. This theory suggests that if individuals are satisfied with their jobs, they may reciprocate these efforts via OCB [39, 40]. There are considerable empirical evidences that indicated OCB and job satisfaction are positively related $[41,40,39,42,13]$. By the same token, job dissatisfaction may contribute in reverse to OCB; to its imperceptibility.

\subsubsection{Predictors of $O C B$ in the Context of the Institution}

The search for reliable predictors of OCB to figure out the enabling factors has been extensive since the last three decades. Personal dispositions, fairness perception, proper motivation, leadership styles, employee's age, job satisfaction are few of the most commonly mentioned predictors of OCB [13]. In line with this, the respondents were asked the predictors which they may think are the enabling factors for OCB in their context. Their responses were presented by the graph below. Based on the respondents' responses, fairness perception is the most frequently mentioned as predictors of OCB (85.09\%), followed by personal dispositions $(65.79 \%)$ and then followed by leadership styles $(63.04 \%)$ while the least frequently answered is employees age (23.68\%).

The implication is that, according the respondents view, fairness perceptions, personal disposition and leadership styles are the most likely predictors of OCB in the institution context.

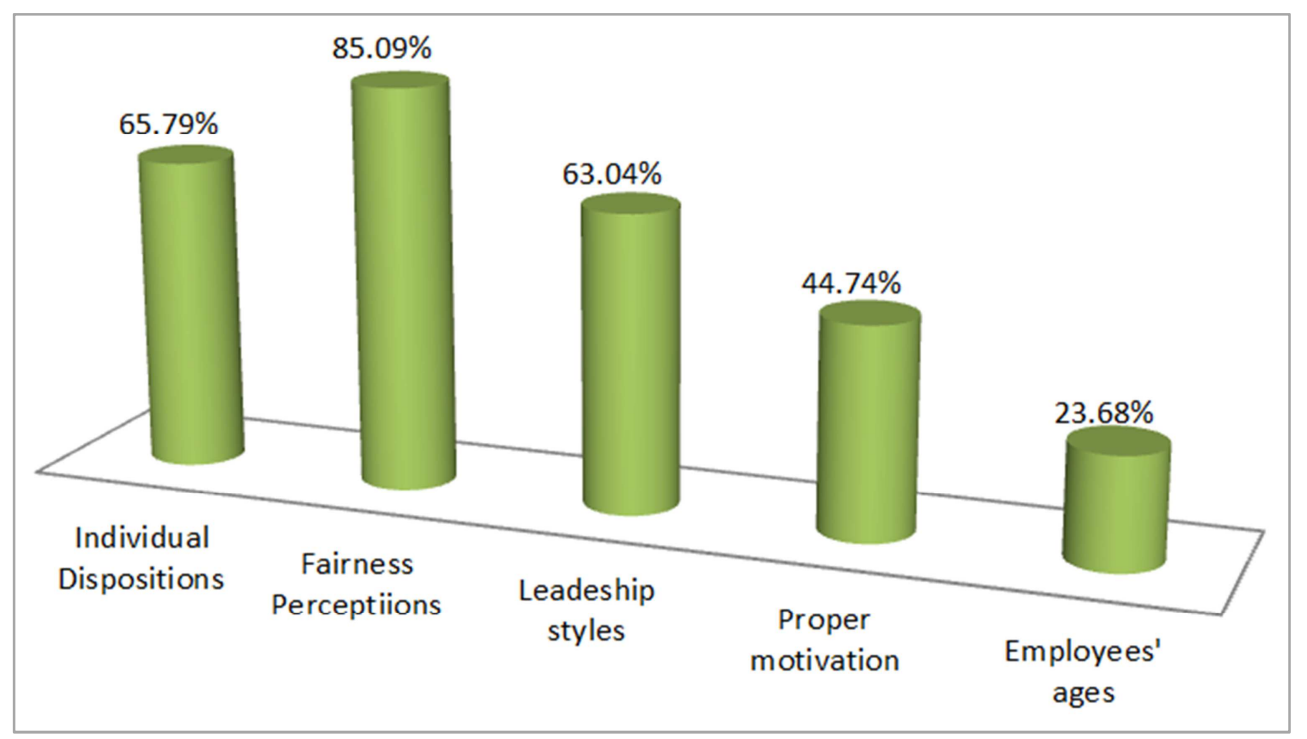

Figure 2. ThePredictors of OCBin the Institutionn in Percentage (Source: researcher's primary data).

\section{Fairness Perceptions}

Fairness or justice perceptions refer to whether or not employees feel organizational decisions are made equitably and with the necessary employee input (procedural justice) and whether or not employees perceive that they are fairly rewarded given their level of training, tenure, responsibility or workload (distributive justice). Perceptions of fairness are positively related to OCB [35].

Individual Dispositions

Individual dispositions arepersonality variables like conscientiousness and agreeableness have been found to predispose people to orientations that make them more likely to engage in OCB [43].

Employee age

Wagner and Rush [44] pointed out that early years are the years of establishment and settling down; later years are strong sense of self and location vis-à-vis life and work. The authors argued that younger employees coordinate their needs with organizational needs more flexibly. By contrast, older employees tend to be more rigid in adjusting their needs with the organization. 


\subsection{Inferential Analysis}

In this section, the results of the inferential statistical techniques used in the study were presented and interpreted. This section was dedicated to answer particularly the research question, "is there the relationship between OCB dimensions and employees performance?" In order to test the research hypotheses related to this research questions, Spearman Correction was employed. As stated in the work of Gogtay and Thatte [45], the Pearson's correlation coefficient establishes a relationship between two variables based on the assumptions of linear relationship, normal distribution and non-categorical variables. Spearman correlation is used when the assumptions of these are not met [46]. Spearman's rho can thus be considered as the non-parametric equivalent of the Pearson's coefficient. Furthermore, Murray [47] showed that parametric and non- parametric tests such as Pearson and Spearman rho conducted on Likert scale data do not affect the conclusions drawn from the results.

In this current study, both the predictors and dependent variables are categorical variables. In addition, the scatter plots of the data for variables showed monotonic relation rather than the linear relation which clearly suggested the researcher the appropriateness of the Spearman correlation.

\subsubsection{Relationship Between Conscientiousness and Employees Performance}

This research study, initially hypothesized there is a significant and a strong correlation between conscientiousness and employees performance which was stated as follows:

$\mathrm{Ho}_{1}$ : There is a significant and strong association between conscientiousness and organizational performance.

According to Organ [19] conscientiousness is discretionary behavior that goes well beyond minimum role requirement of the organization. It refers to behaviors indicating that an individual pays special attention when carrying out one's own work, for example scrupulously sticking to protocol or keeping working hours precisely. Conscientiousness indicates if a particular individual is organized, accountable and hardworking [8]. According to Eby [48], a conscientious individual is competent, well-organized, duty-bound, disciplined, and deliberative. The trait characterizes a person who is achievement oriented. Conscientious people tend to be highly achievement focused and show great perseverance, which explains the high significance of this factor in career success [49]. Conscientiousness is a personality dimension that can be defined as the magnitude of adherence to the rules and norms of an organizational setting. Conscientiousness can also help to make the environment of the organization better and calm and it can help to make affable relationship with peers [5]. Most of these scholars and many assessed the association between conscientious and employee performance that showed a weak but significant correlation between the two variables.

The current study analyzed whether there is inherent relationship between conscientiousnessas predictor variable and employees performance as dependent variable. The
Spearman correction result between the two variables was chosen as the statistical measure to address this hypothesis. The correlational analysis showed that there is a significant relationship between the two variables $(\mathrm{r}=0.296, \mathrm{p}=0.01)$. As a result, the finding revealed that conscientious is significantly associated with employees' performance. Although the hypothesis's test result supported that there is a significant relationship between the two variables, the hypothesis that there is a strong relation between the two variables was not supported by the result as it showed weak relationship $(\mathrm{r}=0.296)$ rather than a strong relationship.

This research finding is consistent with work of Klang [49] which revealed a significant positive correlation between conscientiousness and employees performance with correlation coefficient almost the same value $(\mathrm{r}=0.22)$ as that of current study. Many other reach findings showed correlation of conscientiousness, and employee's performance. Furthermore, the correlations are weak which are shown to be between 0.15 and 0.25 [43]. The current work supports earlier findings that the correlation value for these two variables lies in weak range of correlation coefficient values.

\subsubsection{Relationship Between Altruism and Employees Performance}

The second research hypothesis of this research was analyzed in the same manner as the first one using Spearman correlation coefficient to examine the association between the two variables. This hypothesis states that "there is a significant and strong relationship between altruism and employees performance".

Altruism is a kind of discretionary behavior tailored towards helping and motivating other employees in discharging their duties efficiently and tackles the works related problems [50]. It refers to the healthful and effective functions like creation of friendship, empathy and sympathy among the colleagues which helps them directly or indirectly in order to solve their working problems [11]. Altruism reflects willingness of an employee to help a coworker and it is explained as the selflessness of an employee towards organization [5]. This is highly required in service rendering organization including universities where there is high human interaction. Altruism encourages teamwork and cooperation, allowing employees to increase the pool of available knowledge and thus expected to increase employees' and organizational performance.

In this research study, the association between employees performance and altruism was examined which indicated a significant correlation between these two variables. Cohen [51] classified correlation coefficient values into ranges based their strengths as weak, moderate, strong and very strong. Based on this classification, correlation coefficient value of 0.507 falls in the strong range. Unlike the other two dimensions of OCB considered in this research study, altruism showed a significant as well as a strong correlation with employees' performance $(r=0.507, p=0.01)$. The work of Baghkhasti and Enayati [11] showed significant 
relationship between employee performance and civic virtue, and employee performance and conscientiousness. Their study is, however, in sharp contrast to the current study with respect to the relationship between employee performance and altruism. In this current study, altruism was found to be significantly correlated with employee performance with greatest strength as compared to other dimensions of OCB, but their study did not indicate a significant relationship between the two variables.

On the other hand, previous studies like [21, 22, 23, 49, 52] and many others are consistent with current study with respect to relationship between altruism and employees' performance both in direction and strength.

\subsubsection{Relationship Between Civic Virtue and Employees Performance}

The third hypothesis of hypothesizes that "there no a significant and a strong association between civic virtue and employees performance." To test this hypothesis, statistical tools used for former variables were employed similarly. Civic virtue is participating in the life and culture of the organization and it is not considered behavior which is targeted at individuals rather this behavior targets the organization. It includes behaviors showing a strong sense of responsibility toward the organization, for example, offering advice and suggestions, trying to solve problems, actively parting in the organization's meetings $[19,5]$.

It promotes the interests of the organization broadly; participants voluntarily serve on committees and attend functions [53]. An employee with civic virtue defends the reputation of his /her organization; observes opportunities and threats regarding his /her organization; improves and renews oneself more than the others and follows the changes in the organization closely $[23,54]$.

Literature review shows that civic virtue improves organizational efficiency. The association of this construct with employees' performance as well organizational performance was also exhaustively analyzed. Although most of these research works are in Western geographical and cultural context. Scholars argue that differences in geographical and cultural contexts affect organizational citizenship behaviors differently. It is with this in mind that the current study attempted to assess the association of the two variables in African geographical and cultural context, particularly Ethiopia.

In this study, like conscientious and altruism dimensions, civic virtue was shown to be significantly correlated with employees' performance. Like for those aforementioned dimensions of OCB, the correlational analysis showed civic virtue is significantly associated with performances of the institution's employees $(r=0.347, \mathrm{p}=0.01)$. Unlike conscientious which showed week correlation and altruism which showed strong association, civic virtue showed moderate correlation $(\mathrm{r}=0.347)$. This paper made use of Cohen (1992)'s correlation coefficient basis to say weak, moderate and strong correlation.

Overall, the empirical result which was obtained in almost the same environment as this current study is the work of Hazratian et al. [1]. Hazratian and his co-workers assessed the relationship between educational performance and the three OCB dimensions (conscientious, civic virtue and altruism). The finding showed that there was a significant positive relationship between each of these OCB dimensions and educational performance.

\subsection{Limitation and Future Research}

The present study has some of limitations. Although there more dimensions of $\mathrm{OCB}$, Bukhari et al. [55] mentioned that the three overarching dimensions of OCB are altruism, conscientiousness, and civic virtue. It is in line with this idea that only three dimensions of OCB were included. But still it would have been better if more dimensions were included. Furthermore, the research is case study which is only limited to one particular university, Dire Dawa University. Thus, a further research should be carried to make the result more general by encompassing more dimensions of OCB and more universities into the research design.

\section{Conclusion and Recommendation}

\subsection{Conclusion}

Based on the findings, the following conclusions are made:

The study revealed that some major dimensions of $\mathrm{OCB}$ like altruism, civic virtue and conscientiousness are imperceptible in the institution under the study. The study also indicated that organization justice problems in the institution and employees intention to leave the institution are the major reasons for imperceptibility of OCB in the institution. Furthermore, the finding of the study showed that altruism, conscientious and civic virtue dimensions of OCB are positively and significantly correlated with employee's performance. However, the correlational relationship between the predictor variables and dependent variable is found to be strong only between employee's performance and altruism. Moreover, the study indicated that fairness perception; individual disposition and leadership styles are major predictors of OCB under the context of the institution.

\subsection{Recommendation}

Based the findings and the conclusion, the following recommendations are set forth:

1. Since predictors for the imperceptibility of OCB in the institutions like organizational justice problems, lack of employee empowerment and job dissatisfaction are related to human resource management practices; the management of institution should focus on revising its human resource policies and implementing proper human resource management practices to foster OCB among its employees.

2. The institution's management is highly recommended to focus mainly on distributive and procedural justices as they are known to be the booster of OCB where organizational justice problems are there. 
3. The institution should properly deploy supportive and transformational leadership styles as they are believed to be the best remedy in encouraging OCB when there are dwindling senses of it.
4. The university should create a good working environment and care for employee's job satisfaction as they astonishingly reduce voluntary employees' turnover.

\section{Appendix}

\section{Appendix-A: Questionnaires}

Dear Respondent,

A research entitled as "Organizational Citizenship Behavior and Organizational Performance Assessment: The Case of Dire Dawa University." is being conducted by a staff member of Dire Dawa University. The objective of the study is to assess the reasons for the dwindling sense of ownership and imperceptibility of extra-role behaviors among employees of the university with ultimate goal of finding remedies for such bottlenecks to the university's organizational performances.

I thank you for your time, co-operation and concern!!

Instruction for part I: Please indicate the extent to which you agree with statements in the next table by encircling the number that best represents your opinion. Please use the following scale

Table 3. List of standard Questions.

\begin{tabular}{lllll}
\hline I strongly disagree & I disagree & Neutral & I agree & I strongly agree \\
\hline 1 & 2 & 3 & 4 & 5 \\
\hline
\end{tabular}

Your age:

i. $20-30$

ii. $30-40$

iii. $40-50$

iv. Above 50

\begin{tabular}{|c|c|c|c|c|c|c|}
\hline \multirow{2}{*}{1} & \multirow{2}{*}{$\begin{array}{l}\text { Employee's Performance } \\
\text { I am willing to perform all my duties in the institution }\end{array}$} & \multicolumn{4}{|c|}{ some times } & \multirow{2}{*}{$\begin{array}{l}\text { Often } \\
5\end{array}$} \\
\hline & & 1 & 2 & 3 & 4 & \\
\hline 2 & I make sure that I am a always the first one to arrive in the office & 1 & 2 & 3 & 4 & 5 \\
\hline 3 & I have received recommendation for the good quality of my work & 1 & 2 & 3 & 4 & 5 \\
\hline 4 & I have been rated as one of the best performing employees in the institution & 1 & 2 & 3 & 4 & 5 \\
\hline 5 & I apply a lot of effort when performing my task & 1 & 2 & 3 & 4 & 5 \\
\hline 6 & $\begin{array}{l}\text { I leave the office late to do more work for the institution } \\
\text { Altruism }\end{array}$ & 1 & 2 & 3 & 4 & 5 \\
\hline 7 & I give my time to help employees with work- related problems & 1 & 2 & 3 & 4 & 5 \\
\hline 8 & I talk to other employees before taking actions that might affect them & 1 & 2 & 3 & 4 & 5 \\
\hline 9 & I take time out of my day to train and assist new employees & 1 & 2 & 3 & 4 & 5 \\
\hline 10 & I help out other teammates if someone falls behind once own practice & 1 & 2 & 3 & 4 & 5 \\
\hline 11 & I feel a strong sense of belonging to my institution & 1 & 2 & 3 & 4 & 5 \\
\hline 12 & $\begin{array}{l}\text { I fill the gap when others are absent from their jobs } \\
\text { Civic Virtue }\end{array}$ & 1 & 2 & 3 & 4 & 5 \\
\hline 13 & I really feel as if this institution's problems are my own problems & 1 & 2 & 3 & 4 & 5 \\
\hline 14 & I am eager to tell outsiders about the good of the institution & 1 & 2 & 3 & 4 & 5 \\
\hline 15 & I am willing to stand up to protect the reputation of the institution & 1 & 2 & 3 & 4 & 5 \\
\hline 16 & I actively attend the institution's meetings & 1 & 2 & 3 & 4 & 5 \\
\hline 17 & I do not mind taking on new challenging assignments & 1 & 2 & 3 & 4 & 5 \\
\hline \multirow[t]{2}{*}{18} & I make constructive suggestions that improve the university's operations & 1 & 2 & 3 & 4 & 5 \\
\hline & Conscientious & & & & & \\
\hline 19 & I attend activities that are not normally required of me but help the institution's image & 1 & 2 & 3 & 4 & 5 \\
\hline 20 & I often arrives early and starts to work immediately & 1 & 2 & 3 & 4 & 5 \\
\hline 21 & $\begin{array}{l}\text { I obey the institution's rules and procedures even when no one is watching and no } \\
\text { evidence can be traced }\end{array}$ & 1 & 2 & 3 & 4 & 5 \\
\hline 22 & I believe in giving a honest day for an honest day's pay & 1 & 2 & 3 & 4 & 5 \\
\hline 23 & My attendance at work is above the expected & 1 & 2 & 3 & 4 & 5 \\
\hline 24 & I do not take extra breaks & 1 & 2 & 3 & 4 & 5 \\
\hline
\end{tabular}

Instruction for part II: For the following three open-ended questions, you are kindly requested to choose from the given alternatives by encircling your choice from the options. In case your opinion is not matching with the given alternatives, you can write in the blank space provided.

1. Do you think that employees of the institution have strong sense of ownership to the institution and perform above their 
expected roles?

A. Yes

B. No

If your answer to the above question is No, what will be the reason for disengagement in extra-role performance and lack of sense of ownership? Choose from the given options below. Two or more answers are possible.

A. organizational justice problems like lack of fair decisions by the top level management, lack of fair payment for fair performance and lack of fair treatment by top levels managers.

B. lack of employees' empowerment

C. intentions of employees to leave the institution

D. Job dissatisfaction

E. employees' lack of concern for citizens

Please mention if you have other reasons.

2. Which activities of the institution are directly or indirectly affected by the imperceptibility of sense of ownership and disengagement in extra-role performance by the employees? Two or more answers are possible.

A. the overall performance of the institution

B. the social responsibility of the institution

C. the image of the institution

D. Products (educated students)

E. Community services rendered by the institution

Please mention any other thing you consider can directly or indirectly be affected by the imperceptibility of extra-role performance of employees and lack of sense of ownership.

3. Which of the following do you think will be the antecedent (causes) of organizational citizenship behavior? Two or more answers are possible.
A. Individual dispositions
B. Employees' age
C. Proper motivation
D. Fairness perceptions
E. all

Please mention any other factors you consider that will promote organizational citizenship behavior in any institution.

\section{Appendix-B: Correlation Test Results}

Table 4. Correlation between Organizational Performance and Altruism.

\begin{tabular}{|c|c|c|c|c|}
\hline \multicolumn{5}{|l|}{ a. Correlations } \\
\hline & & & Organizational performance & Altruism \\
\hline \multirow{6}{*}{ Spearman's rho } & & Correlation Coefficient & 1.000 & $.507^{* *}$ \\
\hline & Organizational performance & Sig. (2-tailed) & & .000 \\
\hline & & $\mathrm{N}$ & 114 & 114 \\
\hline & & Correlation Coefficient & $.507^{* *}$ & 1.000 \\
\hline & Altruism & Sig. (2-tailed) & .000 & \\
\hline & & $\mathrm{N}$ & 114 & 114 \\
\hline
\end{tabular}

**. Correlation is significant at the 0.01 level (2-tailed).

Table 5. Correlation between Organizational Performance and Civic Virtue.

\begin{tabular}{lllll}
\hline b. Correlations & & & & \\
\hline & & & Organizational performance & Civic Virtue \\
\hline & \multirow{4}{*}{ Organizational performance } & Correlation Coefficient & 1.000 & $.347^{* *}$ \\
& & Sig. (2-tailed) &. & .000 \\
Spearman's rho & & $\mathrm{N}$ & 114 & 114 \\
& & Correlation Coefficient & $.347^{* *}$ & 1.000 \\
& \multirow{2}{*}{ Civic Virtue } & Sig. (2-tailed) & .000 &. \\
& & $\mathrm{~N}$ & 114 & 114 \\
\hline
\end{tabular}

**. Correlation is significant at the 0.01 level (2-tailed). 
Table 6. Correlation between Organizational Performance and Conscientious.

\begin{tabular}{|c|c|c|c|c|}
\hline \multicolumn{5}{|l|}{ c. Correlations } \\
\hline & & & Organizational performance & Conscientious \\
\hline \multirow{5}{*}{ Spearman's rho } & & Correlation Coefficient & 1.000 & $.296^{* *}$ \\
\hline & Organizational performance & Sig. (2-tailed) & & .001 \\
\hline & & Correlation Coefficient & $.296^{* *}$ & 1.000 \\
\hline & Conscientious & Sig. (2-tailed) & .001 & . \\
\hline & & $\mathrm{N}$ & 114 & 114 \\
\hline
\end{tabular}

**. Correlation is significant at the 0.01 level (2-tailed).

\section{References}

[1] Hazratian T., Khadivi A., Abbasi B. and Ghojazadeh M. (2015). Association Between Organizational Citizenship Behavior and Educational Performance of Faculty Members in Tabriz University of Medical Sciences, Res Dev Med Educ., 4 (1), 81-84.

[2] Alkahtani A. (2015). Organizational Citizenship Behavior (OCB) and Rewards. International Business Research, 8 (4), 210-222.

[3] Podsakoff P. M., MacKenzie S. B., Paine J. B., and Bachrach D. G. (2000). Organizational citizenship behaviors: A critical review of the theoretical and empirical literature and suggestions for future research. Journal of Management, 26 (3), 513-563.

[4] Mushtaq, K. and Umar M. (2015). Association between job satisfaction, motivation and five factors of organizational citizenship behavior. International Journal of Psychological and Behavioral Sciences, 9 (8,), 2872-2878.

[5] Bukhari Z. U (2008). Key Antecedents of Organizational Citizenship Behavior (OCB) in the Banking Sector of Pakistan Ordnance Road, Rawalpindi, Pakistan. International Journal of Business and Management 3 (12), 1-10.

[6] Borman W. C. and Motowidlo, S. J. (1997). Task performance and contextual performance: the meaning for personnel selection research. Human Performance, 10 (2): 99-109.

[7] Darsana I. M. (2014). The Influence of Personality on Employee Performance through Organizational Citizenship Behavior. The International Journal of Management, 3 (4), 1-8.

[8] Nyarieko, M. A; Namusonge G. S, and Iravo M (2017). Impacts of Courtesy, Civic Virtue and Conscientiousness on Casual Employees' Performance: Case Study of Kenya Public Universities. International Journal of Social Science and Economics Invention, 3 (1), 102-110.

[9] Tabassum R. (2016). The Study of Relationship Between Dimensions of Organizational Citizenship Behavior And Gender Difference: A Literature Review. International Journal of Science Technology Management, 5 (2)-300-308.

[10] Kenney, H. (1992). Management Made Easy. $1^{\text {st }}$ edition, South Carolina: Omron Publishers.

[11] Baghkhasti F. And Enayati T. (2015). The Connection between Organizational Citizenship Behavior and Job Performance of the Personnel of Amol City Health Center. Management and Administrative Sciences Review, 4 (2), 429-437.

[12] Organ, D. W. (1997). Organizational citizenship behavior: It's construct clean-up time. Human Performance, 10, 85-98.
[13] Jahangir N., Akbar M. M and Haq M. (2004). Organizational Citizenship Behavior: Its Nature and Antecedents. BRAC University Journal 1 (2), 75-85.

[14] Bolino M. C., Turnley, W. H. Bloodgood J. M. (2002). Citizenship Behavior and the Creation of Social Capital in Organizations. The Academy of Management Review 27 (4), 505-522.

[15] Agustiningsih H. N., Thoyib A, Djumilah H. and Noermijati N (2016). The Effect of Remuneration, Job Satisfaction and OCB on the Employee Performance. Science Journal of Business and Management, 4 (6), 212-222.

[16] Walz S. and Neihoff B. P. (1996). Organizational citizenship behaviors and their effect on organizational effectiveness in limited-menu restaurants, paper presented at Academy of Management Meetings, Cincinnati, $\mathrm{OH}$.

[17] Bateman, T. S. and Organ, D. W. (1983). Job satisfaction and the good soldier: The relationship between affect and employee citizenship. Academy of Management Journal, 26, 587-595.

[18] Dyne L. V., Graham, J. W. and Dienesch R. M. (1994). Organizational citizenship behavior: Construct redefinition, measurement, and validation. Academy of Management Journal, 37, 765-802.

[19] Organ D. W. (1988). Organizational Citizenship Behavior: The good Soldier Syndrome, Lexington, MA: Lexington Books.

[20] Koster F. (2014). "When two worlds collide": Career satisfaction and altruistic organizational citizenship behavior, Int. Journal of Business Science and Applied Management, 9 (1), 1-13.

[21] Hsiung T. L (2014). The relationships among salary, altruistic behavior and job performance in the national basketball association. International Journal of Business and Social Science, 5, 193-196.

[22] Chelagat L. J, and Kiprop P. Ambrose Kemboi (2015). Effect of Organizational Citizenship Behavior on Employee Performance in Banking Sector, Nairobi County, Kenya. International Journal of Business, Humanities and Technology, 5, 55-71.

[23] Barrick M. R., Mount M. K., and Judge T. A. (2001). Personality and performance at the beginning of the new millennium: What do we know and where do we go next? International Journal of Selection and Assessment, 9, 9-30.

[24] Alsuwailem A. and Elnaga A. A (2016). "Exploring the Relationship between Personality and Job Performance" "New Approach". International Journal of Business and Management Invention, 5 (12), 43-53. 
[25] Redman, T. and Snape E. (2005). I to Wed: The Role of Consciousness Transformation in Compassion and Altruism. Journal of Management Studies, 42 (2).

[26] Borman W., PennerL., Allen T. and Motowidlo S. (2001). Personality Predictors of Citizenship Performance. International Journal of Selection and Assessment. 9, 52-69.

[27] Creswell J. W. (2009). Research Design Qualitative, Quantitative, and Mixed Methods Approaches, $3^{\text {rd }}$ edition, SAGE Publications, Inc.

[28] Kotari C. R. (2004): Research Methodology: Methods and techniques, $2^{\text {nd }}$ edition, New Age International.

[29] Sharma V. and Jain S. (2014). Scale for Measuring Organizational Citizenship Behavior in Manufacturing Sector, Pacific Business Review International, 6, 57-64.

[30] Tavakol M. and Dennick R. (2011). Making sense of Cronbach's alpha. International Journal Tabassum R. (2016). The Study of Relationship between Dimensions of Organizational Citizenship Behavior and Gender Difference: A Literature Review. International Journal of science Technology and Management, 5 (5), 300-308.

[31] Alotaibi A. G (2001). Antecedents of Organizational Citizenship Behaviour: A study of Public Personnel in Kuwait, public personnel management, 30 (3), 363-376.

[32] Organ, D. W (1990). The motivational basis of organizational citizenship behavior. Research in Organizational Behavior, Greenwich, CT: JAI Press.

[33] Ince M. and Gul H. (2011). The Effect of Employees' Perceptions of Organizational Justice on Organizational Citizenship Behavior: An Application in Turkish Public Institutions. International Journal of Business and Management, 6 (6), 134-149.

[34] Williams S., Pitre R., and M. Zainuba M. (2002). Justice and Organizational Citizenship Behavior Intentions: Fair Rewards Versus Fair Treatment. The Journal of Social Psychology, 142 (1), 33-44.

[35] Moorman R. H. (1991). Relationship between Organizational Justice and Organizational Citizenship Behaviors: Do Fairness Perceptions Influence Employee Citizenship? Journal of Applied Psychology, 76 (6): 845-855.

[36] Coyne I. and Ong T. (2007). Organizational citizenship behavior and turnover intention: a cross-cultural study, The International Journal of Human Resource Management, 18 (6), 85-97.

[37] Iftikhar M., Shahid M, U., Shahab M. H., Mobeen M. and Qureshi M. (2016). Exploring the Relationship among Organizational Citizenship Behavior, Psychological Empowerment and Turnover Intensions with the Mediating Role of Affective Commitment, International Review of Management and Marketing, 6 (4), 296-304.

[38] Chen X. P., Hui C. and Seg, D. J. (1998). The role of organizational citizenship behavior in turnover: Conceptualization and preliminary tests of key hypothesis. Journal of Applied Psychology, 83 (6), 922-931.

[39] Lee K. and Allen N. J. (2002). Organizational citizenship behavior and workplace deviance: The role of affect and cognitions. Journal of Applied Psychology, 87 (1), 131-142

[40] Kucukbayrak R. (2010). An Integrative Model of
Transformational Leadership, Organizational Commitment, Job Satisfaction and Organizational Citizenship Behavior, MA, Middle East Technical University.

[41] Mohammad J., Habib F. Q and Alias M. A. (2011). Job Satisfaction and Organizational Citizenship Behaviour: An Empirical Study at Higher Learning Institutions, Asian Academy of Management Journal, 16 (2), 149-165.

[42] Williams, L. J., and Anderson, S. E. (1991). Job satisfaction and organizational commitment as predictors of organizational citizenship and in-role behaviors. Journal of Management, 17 (3), 601-617.

[43] Organ D. W and Ryan K. (1995). A meta-analytic review of attitudinal and dispositional predictors of organizational citizenship behavior. Personnel Psychology, 48, 775-802.

[44] Wagner S. and Rush M. (2000). Altruistic organizational citizenship behavior: context, disposition and age, The Journal of Social Psychology, 140, 379-391.

[45] Gogtay N. J. and Thatte U. M. (2017). Principles of Correlation Analysis, Journal of the Association of Physicians of India, 65, 78-81.

[46] Artusi R, Verderio, Pand Marubini E. (2002). Bravais-Pearson and Spearman correlation coefficients: meaning, test of hypothesis and confidence interval, The International Journal of Biological Markers, 17 (2), 148-151.

[47] Murray J. (2013). Likert Data: What to Use, Parametric or Non-Parametric? International Journal of Business and Social Science, 4 (11), 258-265.

[48] Eby, L. T., Sorenson, K. L., and Feldman, D. C. (2005). Predictors of objective and subjective career success: A metaanalysis. Personnel Psychology, 58, 367-408.

[49] Klang A. (2012). The Relationship between Personality and Job Performance in Sales: A Replication of Past Research and an Extension to a Swedish Context. MA thesis. Stockholm University - Department of Psychology.

[50] Kolade O. J, Oluseye O. O, and Osibanjo Omotayo A. O. (2014). Organizational Citizenship Behavior, Hospital Corporate Image and Performance. Journal of Competitiveness, 6 (1), 36-49.

[51] Cohen L. (1992). Power Primer, Psychological Bulletin, 112 (1) $155-159$.

[52] Askarian N., and Eslami H (2013). The Relationship between Personality Traits and Job Performance (Case Study: Employees of the Ministry Of Education of Kerman) Interdisciplinary Journal of Contemporary Research In Business, 5 (8), 322-355.

[53] Castro, C. B. Armario. M. E. and Ruiz M. D. (2004), The influence of employee organizational citizenship behavior on customer loyalty, International Journal of Service Industry Management 15 (1), 27-53.

[54] Ozdem G. (2012). The relationship between the organizational citizenship behaviors and the organizational and professional commitments of secondary school teachers. Journal of Global Strategic Management, 6 (2), 47-64.

[55] Bukhari Z. U.; Ali U.; Shahzad K. and Bashir S. (2009). Determinants of Organizational Citizenship Behavior in Pakistan, International Review of Business Research Papers, 5 (2), 132-150. 